\title{
Do Inimigo do Direito Penal ao Inimigo do Estado Penal ${ }^{1}$
}

From the Enemy of Criminal Law to the Enemy of the Criminal State

\section{MARINA CERQUEIRA ${ }^{2}$}

marinacerqueira61@gmail.com

GALILEU - REVISTA DE DIREITO E ECONOMIA · e-ISSN 2184-1845

Volume XXI $\cdot 1^{\text {st }}$ January Janeiro - 30 ${ }^{\text {TH }}$ June Junho $2020 \cdot$ pp. 197-200

DOI: http://doi.org./10.26619/2184-1845.XXI.1.1.02

Submitted on March $23^{\text {th }}, 2020$. Accepted on June $4^{\text {th }}, 2020$

Submetido em 23 de março, 2020 . Aceite a 4 de junho, 2020

RESUMO 0 presente texto tem como escopo refletir criticamente sobre o Direito Penal do inimigo. Nesse sentido, inicialmente, apresenta-se a função do Direito Penal no Estado Democrático, bem como os seus principais princípios norteadores, a fim de afirmá-lo como instrumento de proteção do sujeito frente ao poder punitivo do Estado. Realizadas tais considerações, premissas básicas para se alcançar a crítica que o trabalho objetiva oferecer, aborda-se a construção do Direito Penal do inimigo e as suas consequências no âmbito da dogmática penal e processual penal. Por fim, pretende-se responder à seguinte questão-problema: o Direito Penal do inimigo possui assento no Estado Democrático?

PALAVRAS-Chave Direito Penal - Direito Penal do Inimigo - Estado Democrático.

ABSTRACT this text aims to critically reflect on the enemy's criminal law. In this sense, initially, the function of Criminal Law in the Democratic State is presented, as well as its main guiding principles, in order to affirm it as an instrument of protection of the subject against the punitive power of the State. Having made these considerations, basic premises for achieving the criticism that the work aims to offer, the construction of the enemy's Criminal Law and its consequences within the scope of criminal and procedural dogma are addressed. Finally, it is intended to answer the following problem question: does the enemy's criminal law have a seat in the Democratic State?

KEYwords Criminal Law - Criminal Law of the Enemy - Democratic State.

Pode-se afirmar, de acordo com Claus Roxin, que a função do Direito penal é a proteção subsidiária de bens jurídicos, assim

1 Este artigo corresponde ao comentário científico da Unidade Curricular de Doutoramento em Direito - Direito: da norma ao procedimento e à fase aplicativa -, lecionada pelo Professor Doutor Manuel Monteiro Guedes Valente.

2 Doutoranda em Direito na Universidade Autónoma de Lisboa. 
compreendidos como conjunto de valores relevantes para a convivência em uma sociedade plural e Democrática ${ }^{3}$. Nesse mesmo horizonte, como bem sustenta Manuel valente, o Direito penal deve exercer a função de equilíbrio consistente em tutelar bens jurídicos, mas, também, proteger o sujeito, acusado da prática de um delito, do violento e arbitrário poder punitivo do Estado ${ }^{4}$.

Nesse sentido, Eugênio Raul Zaffaroni afirma que o Direito penal representa o discurso dos juristas que propõe às agências judiciais um sistema orientado de decisões para impulsionar o progresso do Estado Democrático de Direito ${ }^{5}$.

Dessa forma, o Direito penal tem a sua atuação orientada por normas princípios, dentre os quais, destacam-se, apenas a título de ilustração, os princípios da legalidade, da culpabilidade, da ofensividade e, por fim, pode-se destacar, ainda, o princípio da intervenção mínima, também compreendido como ultima ratio ${ }^{6}$.

Pode-se constatar, portanto, que o Direito penal só pode ser concebido como instrumento de proteção do sujeito, tratando-o como titular de Direitos humanos. Importante notar, nesse contexto, ainda que sucin- tamente, que o Direito penal deve assumir com a política criminal uma relação de "unidade cooperativa" ", haja vista que a política criminal "é a ciência que subordinada aos vetores da legitimidade e da eficácia e aos princípios ético-filósofico-jurídicos da legalidade, da culpabilidade, da ressocialização e da humanidade, deve debruçar-se sobre as causas do crime, sobre a correta redação dos tipos legais de crime (...) sobre o limite de extensão da aplicação do Direito penal de que dispõe o legislador penal face à liberdade do cidadão" 8 .

Pois bem. Realizadas tais breves, mas relevantes, considerações, cumpre-se indagar por que a formulação teórica do Direito penal do inimigo subverte toda o edifício Democrático que deve sustentar o Direito penal (?).

O funcionalismo sistêmico construído e defendido por Günther Jakobs possui como marco teórico Niklas Luhmann e a sua teoria dos sistemas sociais. De acordo com António Manuel de Almeida Costa, verifica-se que Luhmann, na segunda fase da sua obra, aplica as ideias de auto-referência e da auto-reprodução ou auto-poiese, próprias de $\mathrm{H}$. Maturana e F. Varela, no âmbito da biologia, aos sistemas sociais ${ }^{9}$.

3 Roxin, Claus - Novos estudos de direito penal. Organização: Alaor Leite; tradução: Luís Greco, $1 .^{\text {a }}$ Edição, Marcial Pons, São Paulo, 2014, pp.41-66.

4 Valente, Manuel Monteiro Guedes - Direito Penal do Inimigo e o Terrorismo: 0 «Progresso ao retrocesso». $3 .{ }^{a}$ Edição, Editora Almedina, 2019, p. 130.

5 Zaffaroni, Eugênio Raúl - Estructura Básica Del Derecho Penal. $1^{\text {a }}$ Edição, Editora Ediar, Buenos Aires, 2009, pp.14-16.

6 Semer, Marcelo - Princípios Penais no Estado Democrático - Col. Para Entender Direito. Editora Estúdio Editores. com, 2014, p. 33.

7 Reinhart Maurach e Heinz Zipf apud Valente, Manuel Monteiro Guedes - Direito Penal: Fundamentos PolíticoCriminais.Lisboa: Edição de Autor, 2017, p. 91.

8 VAlente, Manuel Monteiro Guedes - Direito Penal: Fundamentos ..., p. 105.

9 Costa, António Manuel de Almeida - O Funcionalismo Sistémico de N. Luhmann e os seus reflexos no Universo Jurídico. Editora Almedina, 2018, p. 81. 
De acordo com essa perspectiva, pode-se afirmar que o Direito, enquanto sub-sistema social, é também um sistema auto-referente, "cujo desempenho ocorre em auto-contacto, subordinando-se ao esquema da recursividade autopoiética ${ }^{10 "}$, que possui como função a estabilização das expectativas normativas, e é compreendido, sob o prisma normativo, como um sistema fechado que, de acordo com o seu código (justo/injusto) estabelece comunicações com outros subsistemas sem que, contudo, interfiram na sua própria lógica de operacionalidade $^{11}$. Assim, se ocorre a violação da norma, por meio da prática de um crime, a pena, que representa uma aplicação contra-fática da sanção, torna-se necessária para restabelecer a vigência da norma e a estabilidade sistêmica: teoria da prevenção geral positiva. Com efeito, o Direito penal do inimigo estabelece uma separação entre a categoria 'pessoa'- aquele cidadão que respeita o comando normativo - e, por outro lado, 'não pessoa', ou seja, aqueles 'não cidadãos' que violam as normas instituídas pelo Estado e que, portanto, não devem merecer sua proteção ${ }^{12}$.
Nessa perspectiva, ao dito inimigo, seria legítimo afirmar que o Estado pode lançar mão de práticas antidemocráticas e, pois, antigarantistas, como por exemplo, a antecipação da tutela penal, impulsionando um - odioso - direito penal do autor, a criação desenfreada de novo crimes, a despeito de não haver nenhum bem jurídico a proteger, bem como a adoção de mecanismos processuais que não respeitam o duo process of law, pois, o único objetivo reside na estabilização das expectativas normativas e, pois, a perfeita vigência da norma e o funcionamento do sistema jurídico. Dito mais claramente, protege-se a sociedade daquele inimigo ${ }^{13}$.

Não se pode deixar de notar, ainda nesse contexto, que as características da sociedade atual servem para fortalecer a adoção do Direito penal do inimigo. Ulrich Beck define a sociedade contemporânea como "sociedade de risco" ${ }^{14}$ que, por sua vez, impulsiona o que Jesus Maria Silva Sánchez denomina de "La expansión del Derecho penal" ${ }^{15}$, pois, com o apoio da cultura do terror midiático, a sociedade clama, a cada dia, por mais rigor na intervenção penal, ainda que implique em tratar o sujeito,

10 Costa, António Manuel de Almeida - O Funcionalismo Sistémico de N. Luhmann ..., p. 85.

11 Costa, António Manuel de Almeida - O Funcionalismo Sistémico de N. Luhmann ..., p. 85.

12 Jakobs, Günther; CANcio Meliá, Manuel - Direito Penal do Inimigo: Noções e críticas. Organização e Tradução: André Luís Callegari e Nereu José Giacomolli, 6. ${ }^{a}$ edição, Livraria do Advogado Editora, Porto Alegre, 2012 , p. 47.

13 VAlente, Manuel Monteiro Guedes - «Os Direitos Humanos e o Direito Penal: uma (re) humanização emergente». In: Estudo em Homenagem ao Prof. Doutor Manuel da Costa Andrade. Vol. II, Direito Processual Penal. Organizadores: José de Faria Costa, Anabela Miranda Rodrigues, Maria João Antunes, Helena Moniz, Nuno Brandão e Sónia Fidalgo, 2017, pp. 285-292

14 BECK, Ulrich - Sociedade de risco: rumo a uma outra modernidade. Tradução: Sebastião Nascimento, Editora 34, São Paulo, 2010, pp.23-28.

15 Silva SÁnchez, Jesús María - La expansión del Derecho penal: Aspectos de la Política criminal en las sociedades postindustriales. 3. ${ }^{\mathrm{a}}$ edição, Editora Edisofer S.l, Libros Juridicos, 2011, p. 11. 
GALILEU : e-ISSN 2184-1845 - Volume XXI - Issue Fascículo 1 - $1^{\text {st }}$ July Julho $-31^{\text {th }}$ December Dezembro 2019 : pp. 197-200

acusado da prática de crime, como coisa, acreditando na equação: "segurança + justiça = liberdade"16. Observa-se, portanto, nos dias atuais, a existência de um verdadeiro Estado Penal que, em prol da segurança nacional, está disposto a aniquilar direitos, constitucionalmente assegurados, na guerra do combate ao inimigo, ainda que, verdadeiramente, acredite que não é isso que se está a fazer.

Conforme sinaliza Günther Grass, as atrocidades praticadas durante o período Nazista na Alemanha nunca tinham sido consideradas, pelos próprios alemães, como possíveis: “(...) nunca. Eu dizia para mim próprio e a outros, eles diziam para si próprios e a mim: nunca os Alemães fariam uma coisa destas" ${ }^{17}$.

Nesse sentido, diante de tudo que foi brevemente abordado, é possível concluir que, a sociedade moderna deve assumir um compromisso democrático de resistência às mudanças que pretendam transformar o Direito penal em Direito penal belicista, pois, consoante bem sustenta Manuel Valente, do contrário, o que há é a“(...) inversão da conceção de Estado que passa a ser um fim em si mesmo e não um fim de proteção do Ser Humano e da humanidade" ${ }^{\prime 18}$.

\section{REFERÊNCIAS BIBLIOGRÁFICAS}

BECK, Ulrich - Sociedade de risco: rumo a uma outra modernidade. Tradução: Sebastião Nascimento, São Paulo: Editora 34, 2010.
Costa, António Manuel de Almeida - O Funcionalismo Sistémico de N. Luhmann e os seus reflexos no Universo Jurídico. Coimbra: Almedina, 2018.

GrAss, Günter - Escrever depois de Auschwitz. 3. ${ }^{a}$ Edição. Tradução de Helena Topa. Lisboa: Editora Dom Quixote.

JAKobs, Günther; CANCIO MELIÁ, Manuel - Direito Penal do Inimigo: Noções e críticas. Organização e Tradução: André Luís Callegari e Nereu José Giacomolli, 6. ${ }^{\text {a }}$ edição, Porto Alegre: Livraria do Advogado Editora, 2012.

Roxin, Claus - Novos estudos de direito penal. Organização: Alaor Leite; tradução: Luís Greco, 1. ${ }^{a}$ Edição, São Paulo: Marcial Pons, 2014.

Silva Sánchez, Jesús María - La expansión del Derecho penal: Aspectos de la Política criminal em las sociedades postindustriales. $3 .^{\text {a }}$ edição, Editora Edisofer S.l, Libros Juridicos, 2011.

Semer, Marcelo - Princípios Penais no Estado Democrático - Col. Para Entender Direito. Editora Estúdio Editores.com, 2014.

Valente, Manuel Monteiro Guedes - Direito Penal do Inimigo e o Terrorismo o «Progresso ao retrocesso». 3..$^{a}$ Edição - Versão portuguesa. Coimbra: Editora Almedina, 2019.

VAlente, Manuel Monteiro Guedes - Direito Penal: Fundamentos Político-Criminais. Lisboa, 2017.

Valente, Manuel Monteiro Guedes - «Os Direitos Humanos e o Direito Penal: uma (re) humanização emergente». In: Estudo em Homenagem ao Prof. Doutor Manuel da Costa Andrade, Vol. II, Direito Processual Penal. Organizadores: José de Faria Costa, Anabela Miranda Rodrigues, Maria João Antunes, Helena Moniz, Nuno Brandão e Sónia Fidalgo, Coimbra: Instituto Jurídico - FDUC, 2017.

ZAFFARONI, Eugênio Raúl - Estructura Básica Del Derecho Penal. 1. ${ }^{a}$ Edição, Buenos Aires: Editora Ediar, 2009.

16 VALente, Manuel Monteiro Guedes - Direito Penal do Inimigo ..., p. 124.

17 Grass, Günter - Escrever depois de Auschwitz. Tradução de Helena Topa, 3. ${ }^{a}$ edição, Editora Dom Quixote, p. 13.

18 VAlente, Manuel Monteiro Guedes - Direito Penal do Inimigo e ..., p. 112. 